\title{
ALIMENTAÇÃO SAUDÁVEL: A INFLUÊNCIA DOS MEIOS DE COMUNICAÇÃO NA MUDANÇA DE HÁBITOS ALIMENTARES
}

\author{
Maria Tereza Barbosa da Silva ${ }^{1}$; Samara Carolina Fernandes Ferreira ${ }^{2}$ \\ ${ }^{1}$ Acadêmica do Curso de Gastronomia, Centro Universitário de Maringá - UNICESUMAR, Bolsista PIC/ICETI. \\ mariaterezabs@hotmail.com \\ ${ }^{2}$ Orientadora, Mestre
}

\begin{abstract}
RESUMO
O aumento da procura por alimentação fora de casa ocasionou uma série de doenças não existentes no século passado. Com isso a busca de informações sobre alimentação saudável nos dias de hoje está em constante crescimento. A pesquisa tem como objetivo mostrar como os meios de comunicação interferem na mudança de hábitos alimentares, pois com toda a facilidade para obtenção de informações por meio de internet, revistas e opiniões de leigos, os profissionais da área são deixados em segundo plano. Logo para o embasamento teórico da pesquisa está sendo feita a leitura de artigos científicos sobre o tema, aplicando a metodologia de revisão bibliográfica.
\end{abstract}

PALAVRAS-CHAVE: Costume alimentar; Influenciadores Digitais; Mídia; Veículos de informações.

\section{INTRODUÇÃO}

Os avanços tecnológicos, a corrida incessante pelo capital e o produtivíssimo exacerbado, vem causando reflexos no cotidiano das pessoas, e principalmente em sua alimentação. Conforme colocado por Pereira (2013) a industrialização teve grande influência na mudança do estilo de vida das pessoas principalmente pela procura de praticidade na alimentação nos dias de hoje. A falta de tempo presente na sociedade, reduz a preocupação com uma alimentação saudável, aumentando a procura por comidas instantâneas, fast-foods e enlatados, em resumo, comidas prontas e industrializadas. Com isso, a sociedade moderna vem passando por um período de transição nos hábitos alimentares, ocasionando no aumento de doenças não existentes no século passado, e esta, encontra-se ligada diretamente à uma alimentação diária "pobre" em nutrientes. "Isso fica bem expresso quando a alimentação é identificada como causadora das doenças e a sua composição química é hipervalorizada". (VILLAGELIM, 2012, p. 683, apud LIFSCHITZ, 2001, p. 69-83)

Desta maneira, as empresas do ramo alimentar, enxergaram uma necessidade e oportunidade de mudar os hábitos alimentares da população, que está cada vez com a saúde mais precária. É neste cenário de manipulação, aproveitamento e exploração do consumidor vulnerável, é que se pauta esta pesquisa, "A divulgação de propagandas sobre produtos alimentares de forma atrativa e que os associa à estilos de vida desejados" (SANTOS, C. D. C. et. Al, 2012, p.63), visto que propagandas, influenciadores digitais e vários outros meios de comunicação em massa tem incutido a ideia de que uma vida saudável é o que deve ser consumido.

Sendo a problemática desta pesquisa, como o aumento nas buscas de informações através dos meios de comunicação por uma alimentação saudável atinge a sociedade atual? E qual o peso proporcionado pela opinião de influenciadores digitais, famosos e profissionais da área?

\section{MATERIAIS E MÉTODOS}

Este trabalho tem como finalidade revelar como os meios de comunicação influenciam na mudança dos hábitos alimentares, visto que a obtenção de informações a respeito está cada vez mais acessível através da internet, influenciadores digitais, revistas, 
etc. Todo o conhecimento adquirido por estes meios, sem que haja o acompanhamento de um profissional pode ocasionar perigos a saúde.

Se pautando da método hipotético-dedutivo e de revisão bibliográfica, buscando-se artigos científicos da área, nas plataformas como por exemplo Google Acadêmico, Periódcio Capes, Scientific Electronic Library Online - SciELO, entre outros, afim de coletar pesquisas relevantes sobre a temática.

\section{RESULTADOS E DISCUSSÕES}

Com a análise dos artigos coletados para a pesquisa ficou evidente que a alimentação sofre mudanças constantes com o passar do tempo. Desde a saída da mulher para o mercado de trabalho, a alimentação das pessoas mudou drasticamente de comida caseira para alimentos prontos e práticos, o que levou ao aumento do mercado de fastfoods. As mídias impressas e televisão usam seu prestigio para exibir propagandas que influenciam crianças e adolescentes ao consumo de serviço de alimentação rápida, alcançando também os trabalhadores com um curto intervalo para almoço ou lanche. Este modelo de alimentação não fornece todos os nutrientes que o corpo humano necessita para se manter saudável, e a frequência de consumo ocasionou no aparecimento de doenças que não existiam no século passado.

Segundo Pereira (2013) o início da vida profissional da mulher com a ocorrência da revolução industrial dificultou a conciliação das tarefas domesticas. Causando um impacto enorme na alimentação das famílias, ocasionando o aumento da procura por refeições prontas e práticas encontradas facilmente nos grandes centros econômicos, Ainda de acordo com Pereira (2013) o equilíbrio entre dietética e gastronomia não se manteve com decorrer do tempo, no século XX por exemplo, houve um aumentou na influência de hábitos alimentares com relação tanto no modo de preparo como na escolha dos alimentos. "Qualquer coisa que economizasse tempo, acreditava-se, era um trunfo positivo. Que isso pudesse trazer consequências sociais e para a saúde não era imaginado." (ALBALA, 2017, p.243)

Após o surgimento da internet e o mundo de informação presente na rede, Rangel, Lamego e Gomes (2012) afirmam que houve um crescimento exacerbado na busca sobre saúde, alimentação e nutrição, o lado ruim do resultado dessas pesquisas é que existem informações verdadeiras e enganosas, o que gera dificuldade na hora de filtrar as respostas. O crescimento das redes sociais e a aparição dos influenciadores digitais trouxe a população um novo modelo de estilo de vida. Expondo suas vidas, hábitos alimentares e de treino, os blogueiros fitness, motivam muitas pessoas a mudarem sua alimentação e rotina de exercícios. Como citado por Jesus (2017) a rotina alimentar e de exercícios compartilhada nas redes sociais dos influenciadores fitness, atraem pessoas que estão buscando um corpo definido, a observação desses indivíduos através de mídia fotográfica acaba servindo de incentivo para obtenção do resultado desejado.

Toda essa informação de fácil acesso tem seu lado positivo e negativo, mesmo mostrando que ter uma alimentação mais natural e equilibrada traz grandes benefícios, apenas imitar o que o outro mostra na internet sem o acompanhamento de um nutricionista e um educador físico pode trazer mais problemas do que solucionar. Apesar de preocupante, não foram encontradas informações detalhadas sobre quais as complicações a falta de orientação profissional pode trazer a saúde, apenas que o risco existe.

\section{CONSIDERAÇÕES FINAIS}

Até o presente momento, fica claro que desde a revolução industrial, a rotina alimentar dos indivíduos tem estado em constante conflito com a falta de tempo recorrente da vida moderna. A partir do momento em que doenças novas surgiram por conta de uma 
dieta que não supre a quantidade de nutrientes que o corpo necessita, a população começa a buscar informações sobre como driblar essa carência, encontrando na mídia em geral e principalmente na internet o que estão procurando.

Em contrapartida nem tudo que está exposto é correto e direcionado a todos os públicos. "Nesta perspectiva, entende-se que é importante que o nutricionista tenha conhecimento sobre alimentação saudável, [...] visto que este é o profissional habilitado para prescrição de dietas, que devem ser individualizadas, [...]" (SILVEIRA, G.M. et Al, 2019). Uma dieta ou treino deve ser prescritos por profissionais da área para que se obtenha benefícios e não malefícios a essas pessoas.

\section{REFERENCIAS}

LEAL, Daniele. Crescimento da alimentação fora do domicílio. Segurança Alimentar e Nutricional, v. 17, n. 1, p. 123-132, 2010. Disponível em: https://periodicos.sbu.unicamp.br/ojs/index.php/san/article/view/8634806/2725. Acesso em: 20 mar. 2019.

DE ASSIS CÉSAR, Maria Rita; DUARTE, André. Governo dos corpos e escola contemporânea: pedagogia do fitness. Educação \& Realidade, v. 34, n. 2, p. 119-134, 2009. Disponível em: https://seer.ufrgs.br/educacaoerealidade/article/view/8264/5534. Acesso em: 20 mar. 2019.

CAMARGO, Isadora; ESTEVANIM, M.; SILVEIRA, S. C. Cultura participativa e convergente: o cenário que favorece o nascimento dos influenciadores digitais. Revista Communicare, v. 17, p. 102-118. Disponível em: https://casperlibero.edu.br/wpcontent/uploads/2017/09/Artigo-5-Communicare-17-Edi\%C3\%A7\%C3\%A3o-Especial.pdf. Acesso em: 20 mar. 2019.

RANGEL-S, M. L.; LAMEGO, G.; GOMES, A. L. C. Cultura participativa e convergente: o cenário que favorece o nascimento dos influenciadores digitais. PHYSIS: REVISTA DE SAÚDE COLETIVA, [S. I.], v. 22, n. 3, p. 919-939, 2012. Disponível em: http://search.ebscohost.com/login.aspx?direct=true\&db=foh\&AN=91633593\&lang=ptbr\&site=ehost-live. Acesso em: 23 mar. 2019.

VILLAGELIM, Andréa Siliveste Brasil et al. A vida não pode ser feita só de sonhos: reflexões sobre publicidade e alimentação saudável. Ciência \& Saúde Coletiva, v. 17, p. 681-686, 2012. Disponível em:

http://search.ebscohost.com/login.aspx?direct=true\&db=foh\&AN=73832367\&lang=ptbr\&site=ehost-live. Acesso em: 23 mar. 2019.

LOPES, Ilza Leite. Novos paradigmas para avaliação da qualidade da informação em saúde recuperada na Web. Ciência da Informação, v. 33, n. 1, p. 81-90, 2004. Disponível em: http://www.scielo.br/pdf/ci/v33n1/v33n1a10.pdf. Acesso em: 23 mar. 2019.

PEREIRA, Ana Maria. Hábitos Alimentares: Uma Reflexão Histórica. Revista Nutrícias, n. 18, p. 18-20, 2013. Disponível em:

http://www.scielo.mec.pt/scielo.php?script=sci_arttext\&pid=S2182-72302013000300005. Acesso em: 4 jun. 2019. 
SILVEIRA, Mariana Gonçalves et al. Conhecimentos de acadêmicos de Nutrição sobre alimentação saudável e Nutrição Esportiva. Revista Brasileira de Nutrição Esportiva, v. 13, n. 78, p. 227-235, 2019. Disponível em:

http://www.rbne.com.br/index.php/rbne/article/view/1346/878. Acesso em: 5 jun. 2019.

MORETTI, Felipe Azevedo; DE OLIVEIRA, Vanessa Elias; DA SILVA, Edina Mariko Koga. Acesso a informações de saúde na internet: uma questão de saúde pública?. Revista da Associação Médica Brasileira (English Edition), v. 58, n. 6, p. 650-658, 2012.

Disponível em: http://www.scielo.br/pdf/ramb/v58n6/v58n6a08.pdf. Acesso em: 5 jun. 2019.

DE JESUS, Diego Santos Vieira. "VEM, MONSTRO!": SUPLEMENTAÇÃO ALIMENTAR E MASCULINIDADE HEGEMÃ" NICA EM PERFIS DE HOMENS FITNESS NO INSTAGRAM. Recorde: Revista de História do Esporte, v. 10, n. 2, 2017. Disponível em:

http://search.ebscohost.com/login.aspx?direct=true\&db=foh\&AN=128373641\&lang=ptbr\&site=ehost-live. Acesso em: 10 jun. 2019.

BOOG, Maria Cristina Faber. Atuação do nutricionista em saúde pública na promoção da alimentação saudável. Revista Ciếncia \& Saúde, v. 1, n. 1, p. 33-42, 2008. Disponível em: http://revistaseletronicas.pucrs.br/ojs/index.php/faenfi/article/viewFile/3860/2932. Acesso em: 11 jun. 2019.

ALBALA, Ken. Comendo na pós-modernidade: como o comprar, o cozinhar e o comer estão se transformando na Era Digital. Estudos Sociedade e Agricultura, 2017. Disponível em:

http://search.ebscohost.com/login.aspx?direct=true\&db=foh\&AN=126785844\&lang=ptbr\&site=ehost-live. Acesso em: 1 ago. 2019. 